\title{
Effect of Cercosporella rubi on Blackberry Floral Bud Development
}

Melinda R. Lyman and Kenneth J. Curry, Department of Biological Sciences, University of Southern Mississippi, Hattiesburg 39406; Barbara J. Smith, United States Department of Agriculture-Agricultural Research Service, Small Fruit Research Station, Poplarville, MS 39470; and Susan V. Diehl, Department of Forest Products, Mississippi State University, Mississippi State 39762

\begin{abstract}
Lyman, M. R., Curry, K. J., Smith, B. J., and Diehl, S. V. 2004. Effect of Cercosporella rubi on blackberry floral bud development. Plant Dis. 88:195-204.

Rosette, caused by the fungus Cercosporella rubi, is an important blackberry disease in the southeastern United States. This disease severely reduces fruit production, and its management has been erratic due to a limited understanding of the host-pathogen relationship. In this study, we expand on previous histological investigations of the development of $C$. rubi on blackberry at tissue and cellular levels from floral bud initiation through senescence of the flower. Symptomatic and asymptomatic floral buds were examined with light microscopy and both scanning and transmission electron microscopy (SEM and TEM, respectively). Fungal development on the surface of floral buds was examined with SEM. Previous light microscope histological studies were unclear about whether $C$. rubi penetrated host tissue. With TEM, we demonstrated an intimate association between fungal and host cells with no penetration prior to death of the host tissue. C. rubi was present on symptomatic floral buds before development and through senescence. No morphological differences were seen between healthy and diseased floral buds $\leq 5.0$ $\mathrm{mm}$ in diameter other than the presence of $C$. rubi. Necrosis was observed in symptomatic buds at the $6.0-\mathrm{mm}$-diameter stage and progressed through floral senescence.
\end{abstract}

Additional keywords: double blossom, Rubus spp., witches'-brooms

Blackberry rosette is a serious problem for growers in the southeastern United States because it severely reduces fruit production, and its control has been erratic due to a limited understanding of the hostpathogen relationship. This disease is characterized by two symptoms: fascicles of vegetative buds along axils of floricanes (rosettes or witches' brooms), and elongated floral buds with reddish sepals and pink, wrinkled petals (double blossom). Blackberry rosette initially was recognized in 1885 (15), and Plakidas (10) later identified the causal agent as the fungus Cercosporella rubi (G. Wint.) Plakidas. Histological studies of the relationship between this fungus and host tissues were reported by Plakidas (10) and Marroquin et al. (7).

Plakidas (10) established a causal link between $C$. rubi and the development of symptoms by inoculating primocanes with

Corresponding author: B. J. Smith

E-mail: BarbaraSmith@ars.usda.gov

Scholarship support was provided for several years by the Mississippi Association of Plant Pathologists and Nematologists.

Accepted for publication 21 October 2003.

Publication no. D-2003-1208-04R

This article is in the public domain and not copyrightable. It may be freely reprinted with customary crediting of the source. The American Phytopathological Society, 2004. pure cultures of the fungus. C. rubi is present in symptomatic flowers that develop on infected shoots in early spring. Dense networks of hyphae are found within vegetative and floral buds. C. rubi grows on the surfaces of developing vegetative and floral organs and does not appear to penetrate host tissues $(7,10)$. Hyphae are surrounded by an extracellular matrix of unknown function and composition (10).

Rubus spp. have a biennial, aboveground growth habit by which perennial rhizomes give rise to biennial shoots. These biennial shoots, termed primocanes, emerge in the spring and continue to grow until late fall. Primocanes become dormant during winter. These shoots develop flowers the following spring and then are referred to as floricanes. Floral buds develop in cymes in leaf axils on lateral branches of floricanes. Floral development of cv. Shawnee is consistent with Takeda and Wisniewksi's (14) description of cvs. Black Satin and Hull Thornless, where floral initiation begins when an axillary meristem flattens and swells. Sepals, petals, stamens, and carpels differentiate on the surface of this meristem in an acropetal sequence. Carpel primordia form cups that elongate asymmetrically and curl to form stylar canals. Ovule primordia develop during the formation of the stylar canals. Sutures form along the stylar canals upon maturation of ovaries. Both the gynoecium and androecium mature at the same time (14). Fruit are produced during the summer, and floricanes die after fruit mature (8).

The life cycle of $C$. rubi follows the biennial growth pattern of the host (12). Hyphae are enclosed within the ovary and stylar canal during carpel development and are thought to prevent suture formation (10). C. rubi also grows over the surfaces of developing stamens. Both male and female floral organs abort as a result of the growth of $C$. rubi on their surfaces (7). However, no information is available on how $C$. rubi develops on dehisced anthers or how it affects pollen dispersal. Conidia

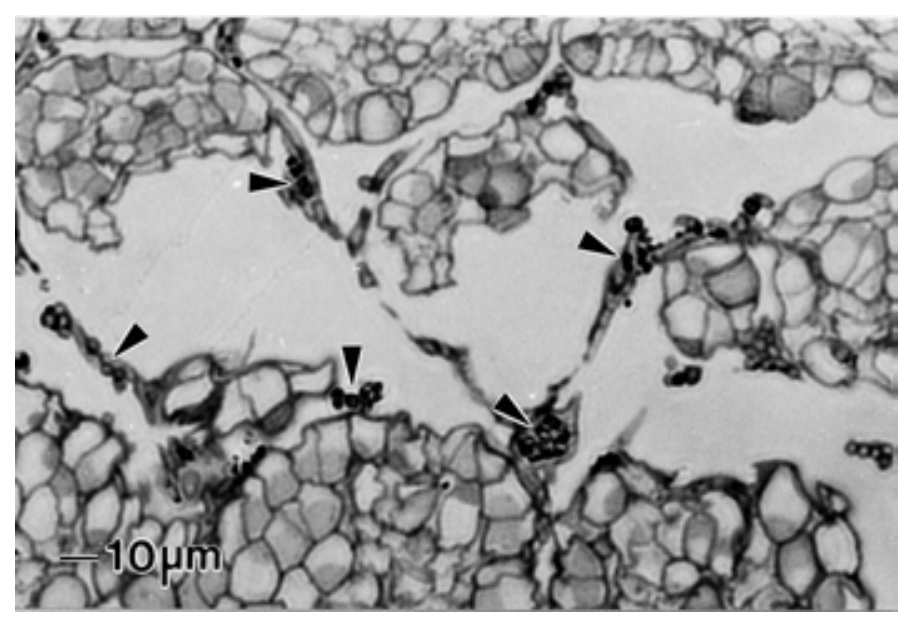

Fig. 1. Light micrograph of a blackberry floral bud less than $1.0 \mathrm{~mm}$ in diameter, infected by Cercosporella rubi, showing typical hyphae surrounded by a characteristic extracellular matrix among floral organs. Arrowheads point to hyphae. 

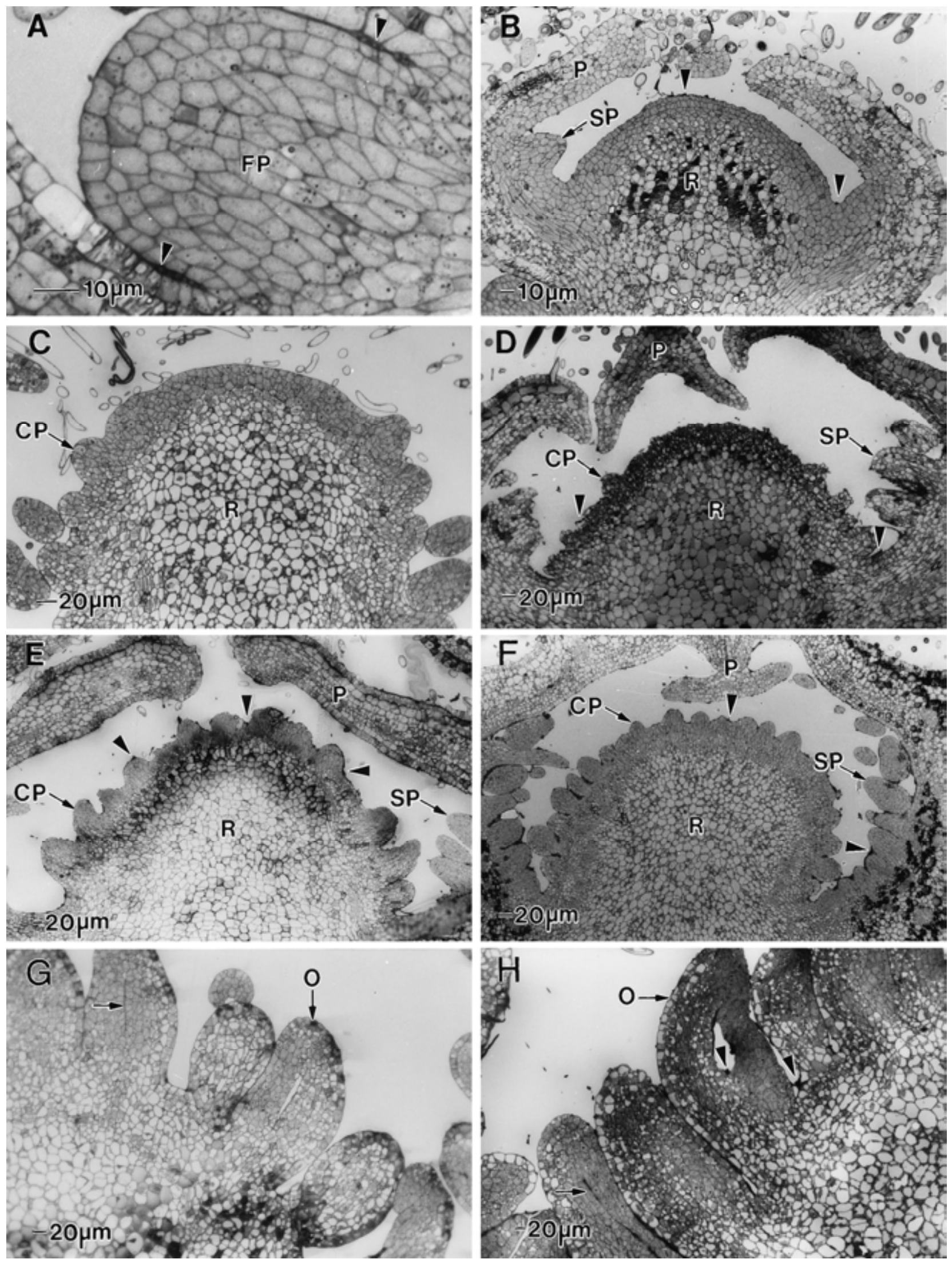

Fig. 2. Light micrographs of blackberry floral buds infected by Cercosporella rubi and healthy buds. A, Infected 0.08-mm-diameter floral primordium (FP) showing no signs of floral organ differentiation. B, Receptacle $(\mathrm{R})$ and infected 0.60 -mm-diameter bud showing signs of floral organ differentiation. Note petals (P) enclose stamen primordia (SP and arrow) (sepals not shown). C, Healthy, 1.0-mm-diameter bud showing receptacle (R) and carpel primordia (CP and arrow). D, Infected, 1.0-mm-diameter bud showing early stages of stamen (SP) and developing carpel primordia (CP). E, Infected bud showing a domeshaped receptacle (R) with carpel primordia (CP and arrow) further along in development than D. F, Infected bud showing a rounded receptacle (R). G, Healthy, 2.0-mm-diameter bud showing ovary (O and arrow) and suture (arrow only). H, Infected 2.0-mm-diameter bud showing hyphae in and among ovaries ( $\mathrm{O}$ and arrow) and in the suture (arrow only). Arrowheads point to hyphae of $C$. rubi. 
are produced on hyphae growing on mature pistils and stamens of open flowers and are dispersed to neighboring primocanes where they are assumed to infect axillary buds (12). The infected floral bud continues to develop with its characteristic symptoms, leading to the appearance of a double blossom at anthesis.

Plakidas (10) demonstrated the optimum growth rate of $C$. rubi in vitro to be $25^{\circ} \mathrm{C}$ and that growth ceased at $31^{\circ} \mathrm{C}$. He also reported that infection did not occur after daytime temperatures exceeded $30^{\circ} \mathrm{C}$, which occurs around 1 June in the southeastern United States and coincides with the beginning of harvest. Smith and Killebrew (13), however, reported that infection may occur as late as mid-July in south Mississippi, which is after the harvest is complete and daytime temperatures exceed $33^{\circ} \mathrm{C}$.

Primocane infection is thought to take place after conidia or hyphae become lodged in vegetative buds and subsequently overwinter in dormant buds (10). Previous histological investigations showed the growth of this fungus on floral buds in relation to development beginning after floral differentiation and ending before senescence $(7,10)$. Plakidas (10) followed development through the stage at which ovaries are fully developed, whereas Marroquin et al. (7) followed it through the petal fall stage. Ovary development is complete before the flower opens; therefore, it is assumed that Plakidas did not examine open flowers microscopically. The "petal drop" stage described by Marroquin et al. (7) is assumed to be sometime after anthesis and before senescence. Whether host cell penetration occurred is also unclear because the data presented were at the tissue level using light microscopy. The objectives of this project were to (i) investigate the relationship of $C . r u b i$ within blackberry flowers through observations of both pathogen and host ontogeny at tissue and cellular levels from before floral differentiation through senescence, and (ii) examine carpel and stamen development in symptomatic and asymptomatic buds.
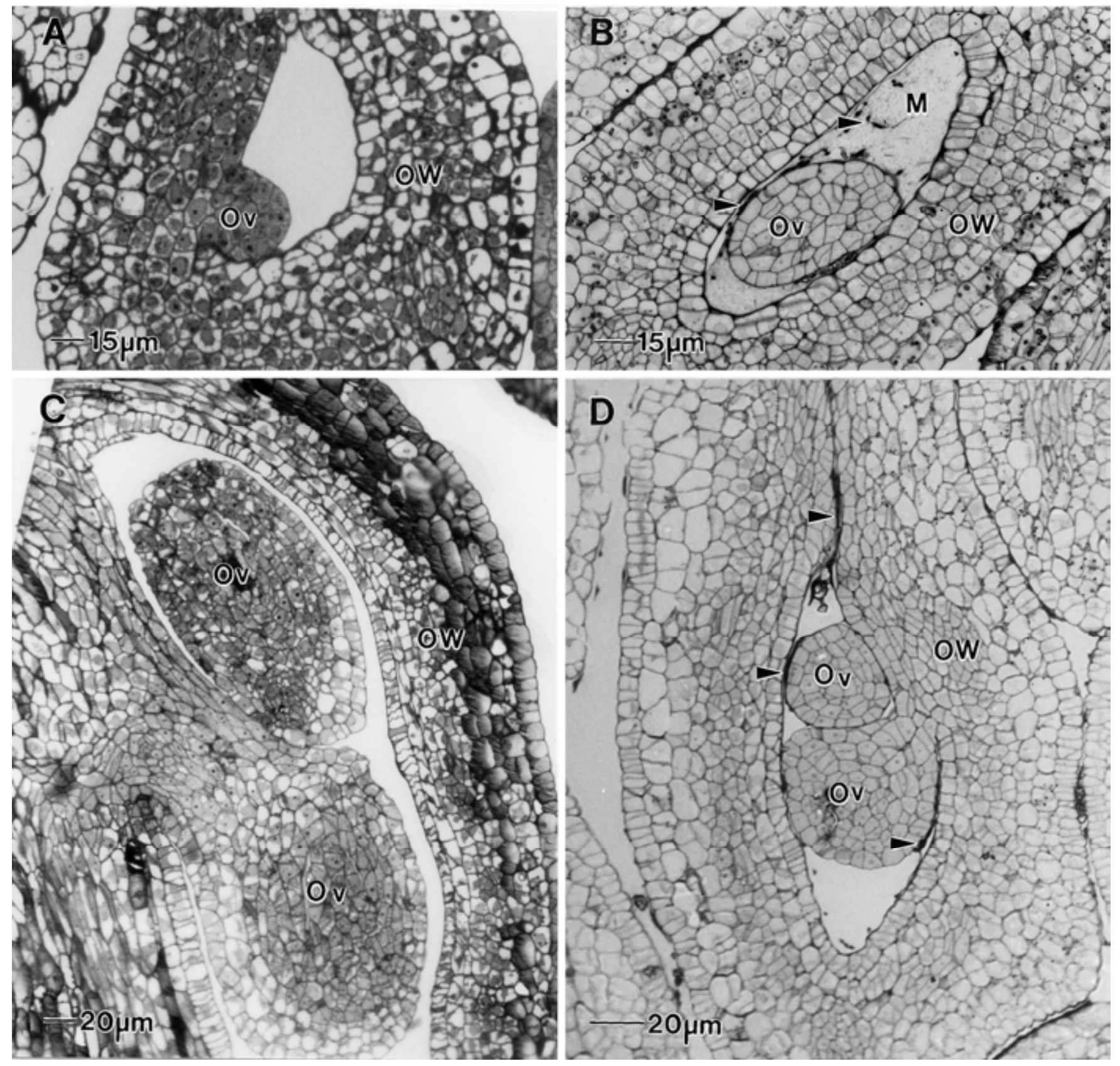

Fig. 3. Light micrographs of blackberry floral buds infected by Cercosporella rubi and healthy buds. A, Healthy, 4.0-mm-diameter bud showing an early ovule (Ov) surrounded by an ovary wall (OW). B, Infected, 4.0-mm-diameter bud showing hyphae sheathed by a matrix (M) surrounding an ovule (Ov). C, Healthy, 5.0-mm-diameter bud showing well developed ovules (Ov) surrounded by an ovary wall (OW). D, Infected, 5.0-mm-diameter bud showing hyphae within an ovary and along the suture that leads to the stylar canal. Arrowheads point to hyphae of $C$. rubi. 

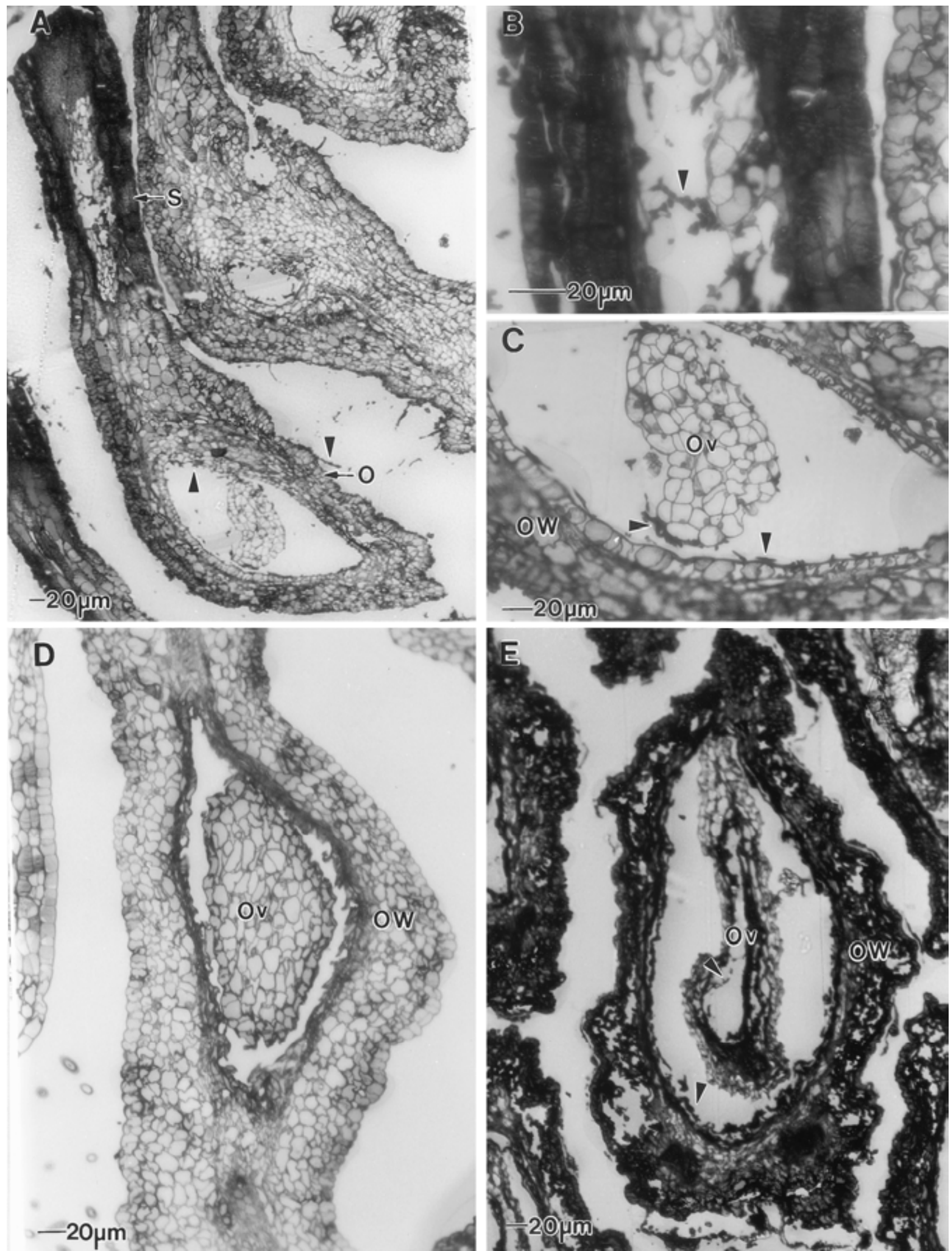

Fig. 4. Light micrographs of carpels of blackberry floral buds infected by Cercosporella rubi and healthy buds. A, Carpel of an infected 6.0-mm-diameter bud showing ovary ( $\mathrm{O}$ and arrow) and style ( $\mathrm{S}$ and arrow). B, Higher magnification of the style showing hyphae in necrotic tissue. $\mathbf{C}$, Higher magnification of the ovary showing hyphae surrounding an ovule $(\mathrm{Ov})$ and appressed to the ovary wall $(\mathrm{OW})$. D, Ovary of healthy, open flower showing an ovule (Ov) surrounded by an ovary wall (OW). E, Ovary of infected, open flower showing a heavily necrotic ovule (Ov) and ovary wall (OW). Arrowheads point to hyphae of $C$. rubi. 


\section{MATERIALS AND METHODS}

Blackberry plants. Field-grown, erect, thorny cultivars of blackberry (Rubus spp.) infected with $C$. rubi were available at the University of Southern Mississippi's Science Park in Hattiesburg, MS and the United States Department of Agriculture (USDA)-Agricultural Research Service (ARS) site in McNeill, MS. Uninfected blackberry plants in containers also were available at the USDA-ARS facility in Poplarville, MS. The focus of this study was the blackberry cv. Shawnee because of its high susceptibility to rosette $(3,5)$; however, five other susceptible cultivars (Brazos, Cherokee, Cheyenne, Commanche, and Rosborough) also were included. Over 40 symptomatic and asymptomatic floral buds of 'Shawnee' and representative buds of the other cultivars were collected in early spring during 2000 and 2001 at various developmental stages, from less than $1.0 \mathrm{~mm}$ in diameter through senescence, for examination by light and electron microscopy. Buds were transported to the laboratory on ice and processed immediately.

Pathogen identification and isolations. At least three symptomatic and three asymptomatic floral buds and open flowers were collected from field-grown plants of each of six blackberry cultivars. In some cases, tissues were examined with a wet mount to confirm the presence of the fungus by its morphology (2). In other cases, the fungus was isolated from surface-disinfested buds by immersing them in a $10 \%$ commercial bleach solution for $15 \mathrm{~min}$., then rinsing three times in sterile distilled water. Each bud then was cut in half and portions of the interior were placed aseptically on acidified potato dextrose agar (APDA) (Beckman Dickinson, Sparks, MD) and incubated for 2 to 3 weeks at room temperature $\left(21 \pm 2^{\circ} \mathrm{C}\right)$ under continuous fluorescent light. Resultant colonies were confirmed as $C$. rubi by colony morphology and microscopic examination of conidiophores and conidia (2).

Tissue processing. Six symptomatic and six asymptomatic floral buds were collected in pairs from each of four cultivars (Brazos, Cheyenne, Rosborough, and Shawnee) at each of five developmental stages from tightly closed through petal fall (7) for the scanning electron microscope (SEM) study. One bud from each pair was examined by SEM and the interior of the other bud was surface disinfested and placed on A-PDA as described above to determine if $C$. rubi was present. For SEM examination, dissected floral buds were fixed in a solution of $2.5 \%$ glutaraldehyde and $0.5 \mathrm{M}$ potassium phosphate buffer $(\mathrm{pH} 7.0)$ overnight at $5^{\circ} \mathrm{C}$. Specimens were rinsed in $0.5 \mathrm{M}$ potassium phosphate buffer ( $\mathrm{pH} 7.0$ ), postfixed in $2 \%$ osmium tetroxide in $0.5 \mathrm{M}$ potassium phosphate buffer ( $\mathrm{pH}$ 7.0) for approximately $8 \mathrm{~h}$, and then rinsed again in $0.5 \mathrm{M}$ potassium phosphate buffer ( $\mathrm{pH} 7.0)$, leaving the final change overnight at $5^{\circ} \mathrm{C}(1)$. A graded series of 35 to $100 \%$ ethanol was used to dehydrate the specimens (1). The specimens then were placed in a critical point drier for approximately $4 \mathrm{~h}$, sputter coated with goldpalladium, and examined with a JEOL
JSM-35CF scanning electron microscope at 20 kV. Photographs were made on Polaroid PN 55 film.

More than 80 samples of the various floral bud sizes $(0.08$ through $>6 \mathrm{~mm})$ were

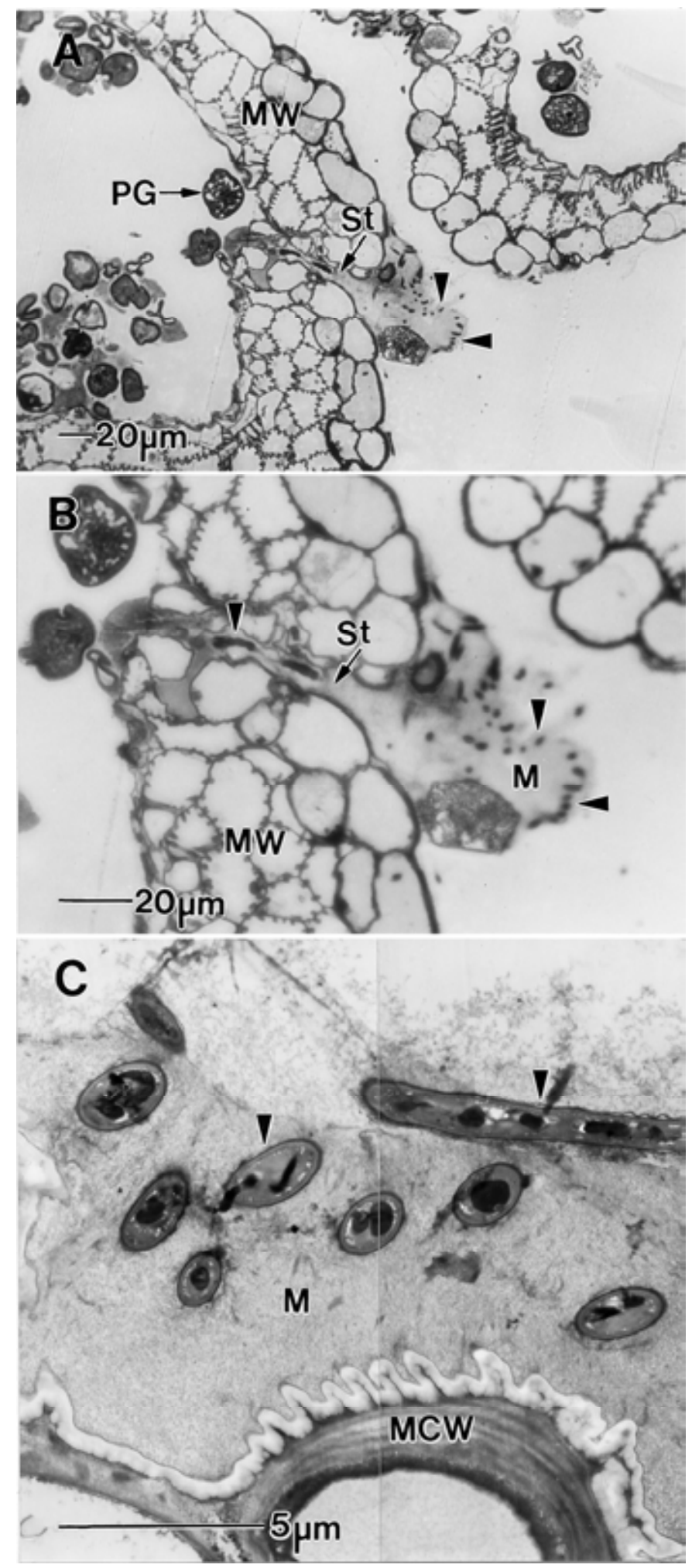

Fig. 5. Anther of a blackberry flower, infected by Cercosporella rubi, just prior to opening. A, Light micrograph of microsporangial cavity showing pollen grains (PG and arrow) enclosed by a microsporangial wall (MW) that has started to split to form the stomium (St). B, Higher magnification of $\mathbf{A}$ showing hyphae in the stomium (St). Note the characteristic matrix (M) surrounding hyphae. $\mathbf{C}$, Transmission electron micrograph of an area just outside a stomium showing hyphae surrounded by matrix (M). MCW = microsporangial cell wall. Arrowheads point to hyphae of $C$. rubi. 
collected for light and transmission electron microscopy (TEM). Each bud was surface disinfested and aseptically cut in half. One half was prepared for pathogen isolation as described above, while the other half was fixed in a solution of $2.5 \%$ glutaraldehyde, $2.0 \%$ formaldehyde, and $0.1 \mathrm{M}$ sodium cacodylate buffer $(\mathrm{pH} 7.0)$ overnight at $5^{\circ} \mathrm{C}$. Bud halves were rinsed in $0.1 \mathrm{M}$ sodium cacodylate buffer $(\mathrm{pH}$ 7.0), postfixed in $1 \%$ osmium tetroxide in $0.1 \mathrm{M}$ sodium cacodylate buffer $(\mathrm{pH} 7.0)$ for approximately $1 \mathrm{~h}$ on a slow-speed, laboratory rotator (Glas-Col, Terre Haute, IN), and then rinsed in distilled water (1). A graded series of 50 to $100 \%$ ethanol and $100 \%$ acetone was used to dehydrate the specimens (1), which then were immersed in a 1:2 vol/vol mixture of acetone and ERL 4206 (Spurr's) epoxy and rotated for $4 \mathrm{~h}$ (6). The specimens were transferred to a 1:4 vol/vol mixture of acetone and resin and rotated overnight, followed by three changes of $100 \%$ resin during $8 \mathrm{~h}$. Resin was cured at $70^{\circ} \mathrm{C}$ for 24 to $48 \mathrm{~h}$ in plastic molds (6). A glass or diamond knife was used to section the specimens on an MT2B Porter-Blum ultramicrotome. For light microscopy, 1- $\mu \mathrm{m}$ sections were stained using $0.01 \%$ toluidine blue-O for $1 \mathrm{~min}$ at $60^{\circ} \mathrm{C}$, rinsed with distilled water, and examined with an Olympus BH-2 brightfield microscope. For electron microscopy, 100$\mathrm{nm}$ sections were collected on copper grids and stained with lead citrate (11) for 15 min followed by aqueous, saturated uranyl acetate for $15 \mathrm{~min}$, using distilled water to rinse the sections between stains. Sections then were examined with a Zeiss EM 10C transmission electron microscope. Photographs were made with Kodak 4489 film.

\section{RESULTS}

Light microscopy. Specimens of $C$. rubi were isolated from all floral buds with detectable rosette symptoms and never from asymptomatic buds. Typical hyphae of $C$. rubi surrounded by a characteristic extracellular matrix among floral organs are shown in Figure 1. Hyphae of $C$. rubi were observed in floral buds before floral differentiation at stages as small as 0.08 $\mathrm{mm}$ in diameter (Fig. 2A). At this stage of floral development, the floral primordium was swollen and rounded, with no signs of floral organ differentiation. Organ differentiation was visible in floral buds $0.60 \mathrm{~mm}$ in diameter (Fig. 2B). Petals were enclosed by sepals, and stamen primordia appeared as small protrusions. The receptacle was a central core of relatively large, vacuolated parenchymatous cells covered by layers of small, densely cytoplasmic cells. Hyphae, sheathed by their fungal matrix, were observed on the surfaces of developing floral organs.

The receptacle continued to expand, and carpel initiation had begun in healthy buds $1.0 \mathrm{~mm}$ in diameter (Fig. 2C). Develop-
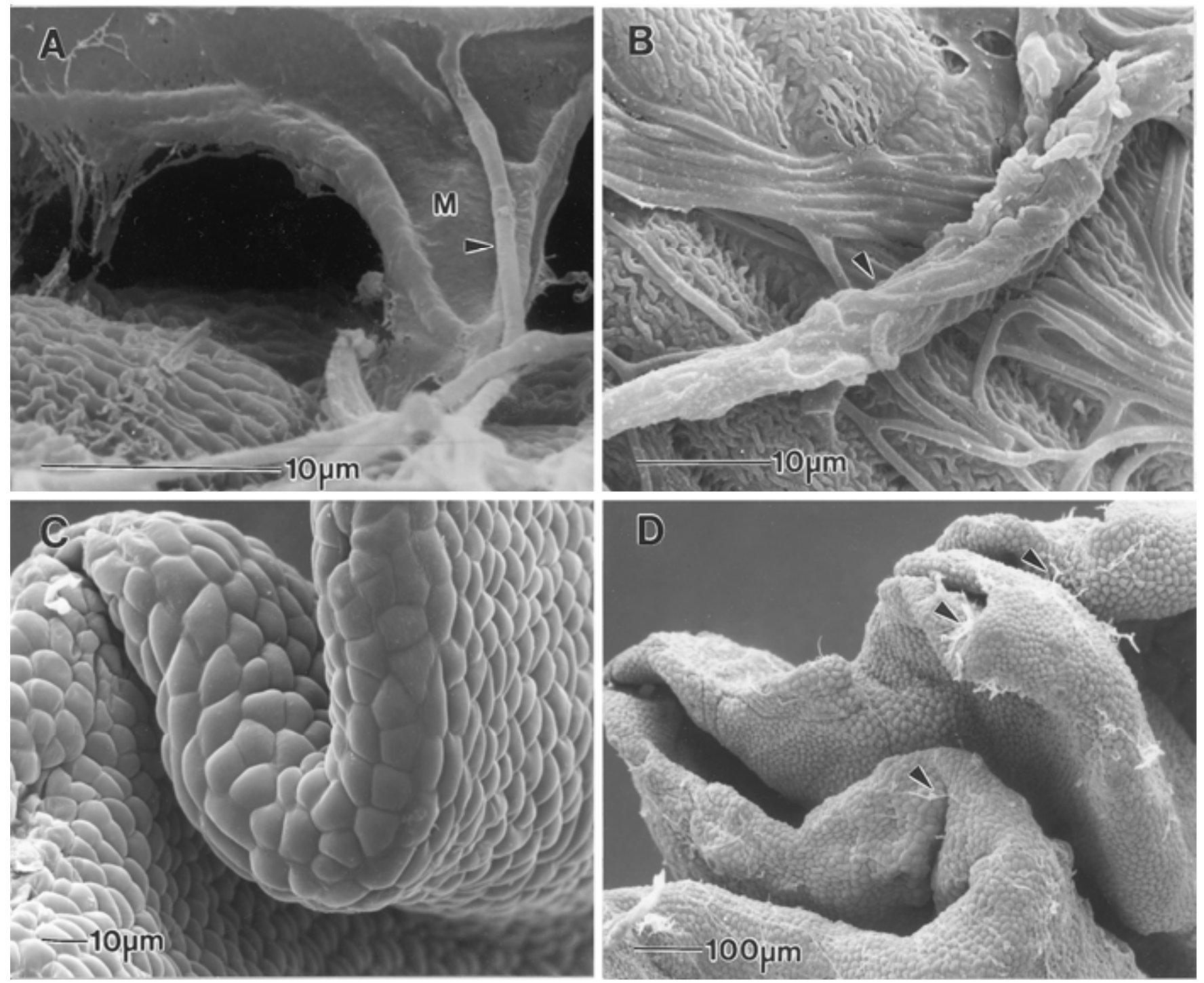

Fig. 6. Scanning electron micrographs of blackberry flowers infected by Cercosporella rubi and healthy flowers, just prior to opening. A, Crevice within an infected 'Cheyenne' flower showing hyphae of $C$. rubi surrounded by its mucilaginous matrix (M). B, Surface of a 'Cheyenne' floral organ showing hyphae intertwined to form a rope-like structure. C, Petal of a healthy 'Shawnee' flower showing smooth margins. D, Petal of an infected 'Shawnee' flower showing hyphae among furrowed margins. Arrowheads point to hyphae of $C$. rubi. 
mental variation was observed in infected floral buds at the 1.0-mm-diameter stage. In some symptomatic floral buds, receptacle development was the same as in asymptomatic floral buds of the same diameter, in that the receptacle was flattened and early stages of stamen and carpel development were apparent (Fig. 2D). Others appeared further along in development, showing carpel primordia as small protuberances along the surface of a domeshaped receptacle (Fig. 2E). However, in others, the receptacle tended to be more rounded (Fig. 2F). Regardless of the developmental variation among infected $1.0-\mathrm{mm}$ floral buds, hyphae occupied the crevices of carpel and stamen primordia (Fig. 2D-F).

Ovaries were well developed and suture formation had begun in both healthy and infected 2.0-mm floral buds (Fig. 2G and $\mathrm{H})$. Ovule development already had begun in 4.0-mm-diameter floral buds (Fig. 3A and B). Style elongation also was evident in floral buds of this diameter. Stigmata, styles, ovaries, and ovules were well de- veloped in 5.0-mm-diameter floral buds (Fig. 3C and D). Hyphae were found among carpels and within ovaries of infected floral buds. Hyphae also were found along the suture of the stylar canal which leads to the ovary (Fig. 3D). Up to the 5.0mm-diameter stage, there were no apparent morphological differences between healthy and infected floral buds other than the presence of $C$. rubi. Hyphae proliferated in crevices of developing organs as floral buds became larger.

Hyphae were observed in necrotic tissue of the style and appressed to the ovary wall and ovule in infected 6.0-mm-diameter floral buds (Fig. 4A-C). There were distinct differences between healthy and infected open flowers. The ovary wall and ovule of infected, open flowers were heavily necrotic, in contrast to those of healthy, open flowers (Fig. 4D and E). Resin infiltration was difficult to accomplish in 6.0mm-diameter and larger asymptomatic floral buds. This probably was due to the tightness of asymptomatic compared with symptomatic buds, which tended to be looser. Problems with resin infiltration put an upper limit on the size of asymptomatic buds observed. Therefore, cellular comparisons of larger asymptomatic buds with those of symptomatic buds of the same size are based on a few samples.

Hyphae were readily observed on the surfaces of stamens at progressive stages of floral development, but were not observed within the microsporangial cavities until they opened upon pollen maturation. An anther of a partially opened flower is shown in Figure 5A. The microsporangium wall had begun to split, and hyphae were found within the cavity (Fig. 5B). Hyphae ultimately occluded this cavity as the stomium continued to open. A transmission electron micrograph of the same sample used in Figure 5A and B is shown in Figure 5C. Hyphae, surrounded by a matrix, are concentrated near the microsporangial cell walls.

SEM. The following observations are based on 'Cheyenne' (Fig. 6A and B),
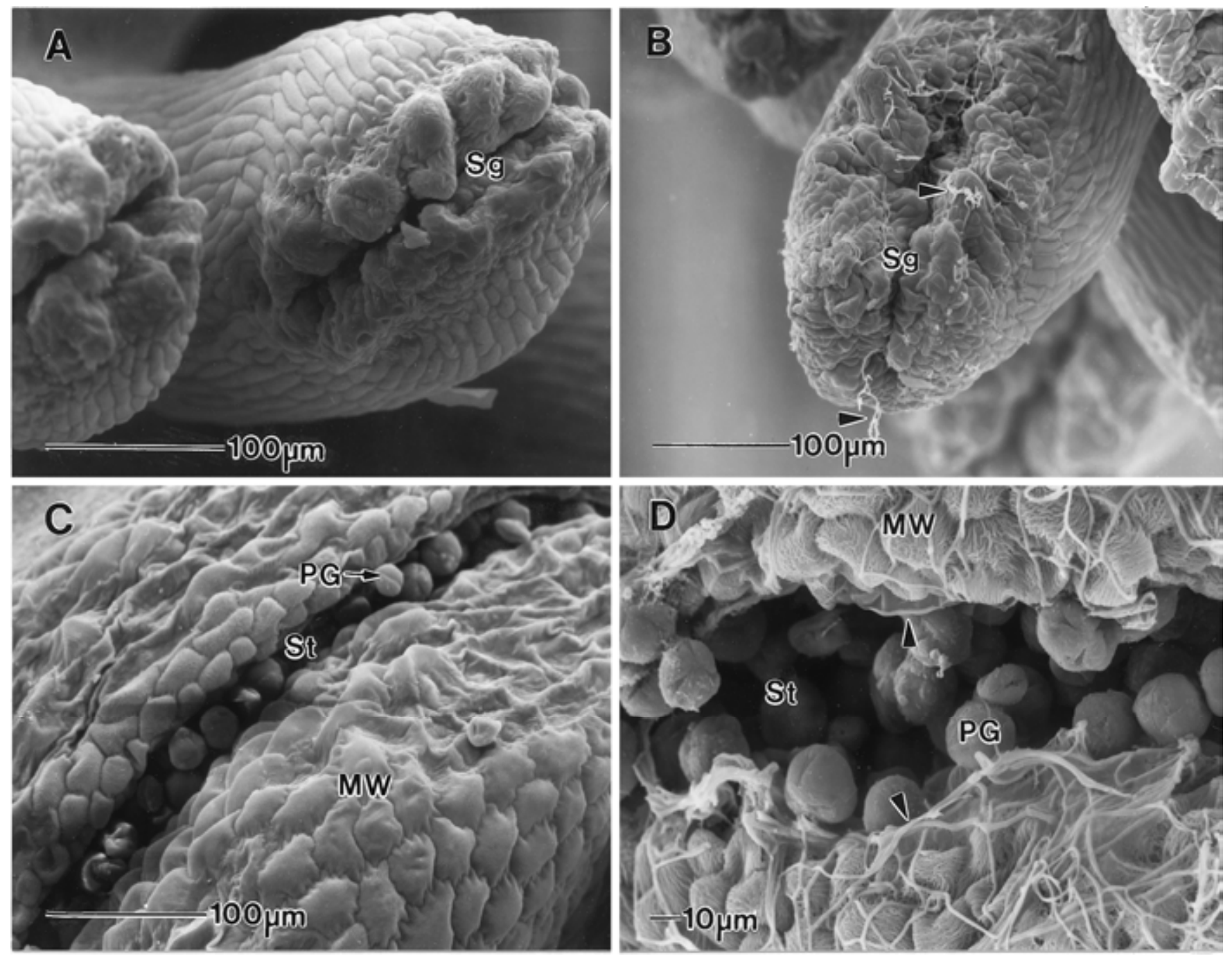

Fig. 7. Scanning electron micrographs of 'Shawnee' blackberry flowers infected by Cercosporella rubi and healthy flowers, just prior to opening. A, Stigma $(\mathrm{Sg})$ of a healthy flower. B, Stigma ( $\mathrm{Sg}$ ) of an infected flower showing hyphae growing along the suture. $\mathbf{C}$, Anther of a healthy flower showing pollen grains (PG and arrow) surrounded by a microsporangial wall (MW) that has started to split to form the stomium (St). D, Anther of an infected flower showing hyphae entering the stomium (St) as it is formed. Arrowheads point to hyphae of C. rubi. 
'Shawnee' (Figs. 6C and D and 7 A-D), 'Brazos', and 'Rosborough' (photographs not shown) flowers just prior to opening. Hyphae were sheathed by a mucilaginous matrix that appeared as bridges among floral organs (Fig. 6A). Hyphae of C. rubi intertwined, forming thick, rope-like structures (Fig. 6B). Petals of infected flowers were more furrowed than those of healthy flowers (Fig. 6C and D). Comparisons between healthy and infected flowers showed hyphae in the suture along the stylar canal and at the stigma of the infected flower (Fig. 7A and B). Comparisons between healthy and infected anthers based on examination by SEM confirmed

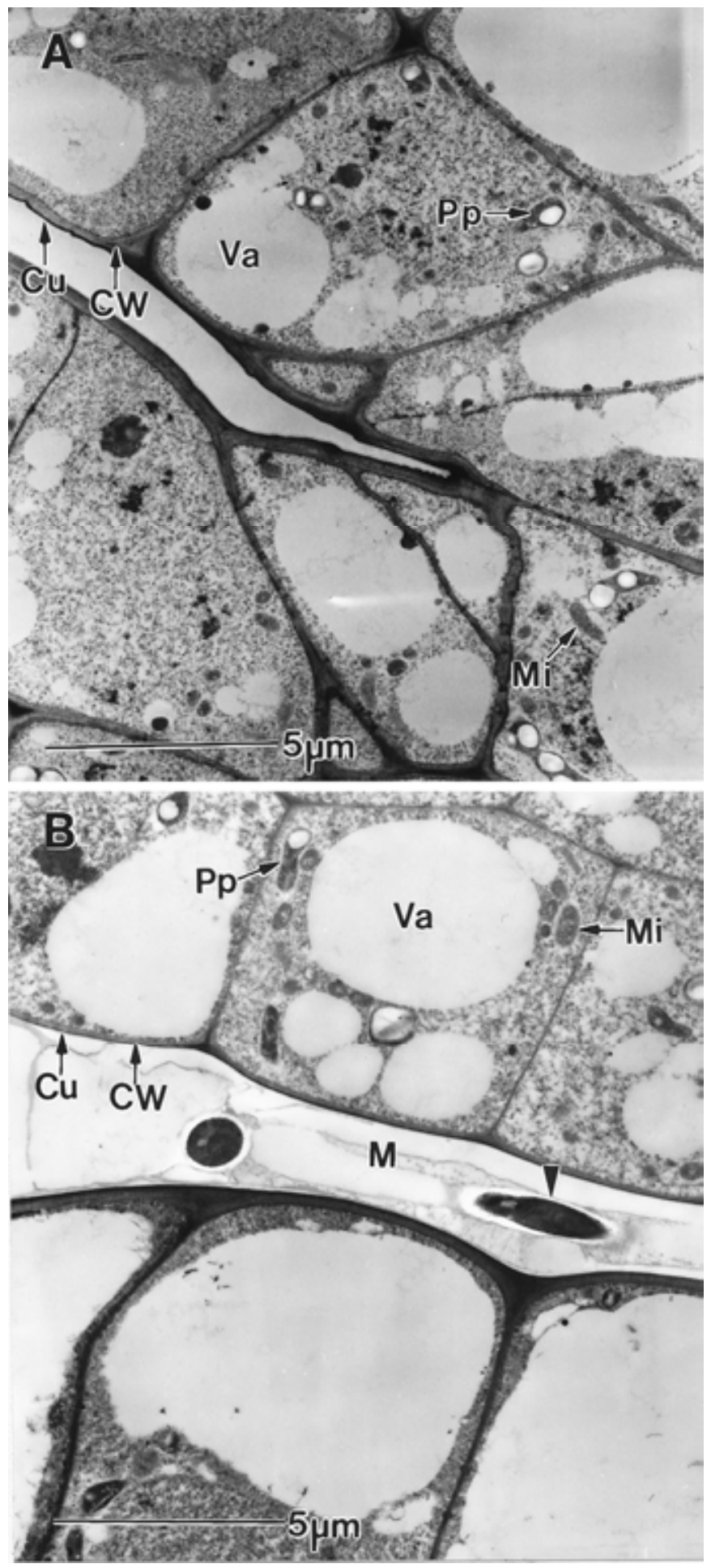

Fig. 8. Transmission electron micrographs of $1.0-\mathrm{mm}$-diameter blackberry floral buds infected by Cercosporella rubi and healthy buds. A, Area between carpels of a healthy bud showing an intact cuticle ( $\mathrm{Cu}$ and arrow), cell wall (CW and arrow), and organelles. B, Area between carpels of an infected bud, but with healthy cells comparable to those in A. Hyphae are surrounded by a granular matrix $(\mathrm{M}) . \mathrm{Va}=$ vacuole; $\mathrm{Pp}$ and arrow $=$ proplastid $; \mathrm{Mi}=$ mitochondrion. Arrowheads point to hyphae of C. rubi.

observations at the light microscopic level that hyphae are in the stomium after it opens (Fig. 7C and D).

TEM. Comparisons between symptomatic and asymptomatic floral buds of the same diameter up to the 5.0-mm-diameter stage showed that host cells generally appeared healthy regardless of the presence of hyphae. The cuticle, cell walls, membranes, and organelles remained intact, indicating no obvious signs of stress (Fig. $8 \mathrm{~A}$ and $\mathrm{B})$. The mucilaginous matrix observed in Figure 6A appeared granular at the ultrastructural level (Fig. 8B).

Infected floral buds showed signs of necrosis as floral buds reached the $6.0-\mathrm{mm}$ diameter stage (Fig. 9A). Cell walls were collapsed and cell organelles and membranes had degenerated into a relatively uniform mass of material. There were extreme differences between healthy and infected open flowers at this stage. Carpels of healthy, open flowers had uniform cells with large vacuoles and intact cell walls (Fig. 9B), whereas cells of infected, open flowers were collapsed with granular vacuoles, and cell walls were difficult to distinguish. Hyphae were visible within these collapsed cells (Fig. 9C).

\section{DISCUSSION}

Our field diagnosis of symptomatic or infected buds and flowers was confirmed by isolation of $C$. rubi or by observation of the fungus within the bud. Likewise, the pathogen never was seen in or isolated from asymptomatic or healthy buds. The histological observations described in this investigation confirm previous reports that C. rubi is present before floral differentiation and persists in open, necrotic flowers. Although C. rubi appears to induce rosette formation, its presence does not appear to alter floral morphology during the early stages of floral development. As the flower reaches anthesis, however, the fungus seems to induce floral abortion by accelerating necrosis which was observed before the flowers opened. C. rubi is known and was observed to sporulate on infected open flowers and was confirmed as the causal fungus through isolation from symptomatic tissue. The cultural characteristics, conidiophores, and conidia of the isolated fungus were consistent with the species description of $C$. rubi $(2,10)$.

Necrosis of infected flowers may be attributed to several factors, all of which may be associated with inhibition of fertilization. Plakidas (10) speculated that hyphae interfering with suture closure during carpel development induced the carpel to abort. This hypothesis is supported by our observations of hyphae in sutures of carpels of 5.0-mm-diameter floral buds and in necrotic ovaries of open flowers. We speculate that, in $6.0-\mathrm{mm}-$ diameter floral buds, hyphae growing through the style may interfere with pollen tube development and, therefore, contrib- 
ute to ovule abortion. C. rubi also may interfere with fertilization by preventing pollen dispersal because hyphae were observed at the stomium.

To our knowledge, this is the first study of $C$. rubi and blackberry host cell interactions at the ultrastructural level and the first to examine this fungus in floral buds from before floral differentiation until senescence. In general, host cells from floral buds less than $6.0 \mathrm{~mm}$ in diameter appeared healthy, even though hyphae, sheathed by a matrix, were closely appressed to the epidermis of developing floral organs. Signs of cellular deterioration began to appear in closed 6.0-mm-diameter floral buds, while hyphae remained on the surface of floral organs. Hyphae were found within the heavily collapsed cells of carpels of infected, open flowers.

Appressoria or hyphal penetrations of host cells were never observed at any point during floral development, yet $C$. rubi appeared in dead host cells when the infected flower opened. How $C$. rubi obtained nutrients during the early stages of floral development is uncertain. We did observe the fungus on dead host tissue and, because no evidence was observed to indicate that this fungus is a necrotroph (i.e., kills host tissue just in advance of its invasion), we must conclude that $C$. rubi is a saprophyte on dead host tissues. Its role as a pathogen is certainly obscure. Any causal pathogen relationship between the fungus and host tissue would have to be addressed by invoking toxins, exoenzymes, or plant growth regulators produced or induced by the fungus. $C$. rubi was the only fungus found on symptomatic floral buds throughout floral development; perhaps this gives it a competitive advantage over other saprophytic fungi that usually colonize moribund tissue, because it is established in host tissue well before senescence (9). Buckley et al. (3) reported cultivar differences in the appearance and survival of rosette-infected tissues. Rosettes of 'Shawnee' were vigorous and remained green for several weeks after harvest, whereas those of 'Rosborough' were stunted and shriveled, and infected canes died before harvest.

Disease management practices have been difficult to establish because there are gaps in understanding how $C$. rubi invades blackberry flowers. Effective management schemes include destroying wild blackberries near the planting site, removing infected shoots when rosettes appear in the early spring, and mowing severely infected floricanes to ground level $(12,13)$. These practices, however, are often ineffective when rosette is severe, and mowing is impractical because it results in a severe reduction in fruit production (13). Planting rosette-resistant cultivars also has been suggested as an alternative management scheme, and several erect, thornless cultivars have been identified as rosette resis-
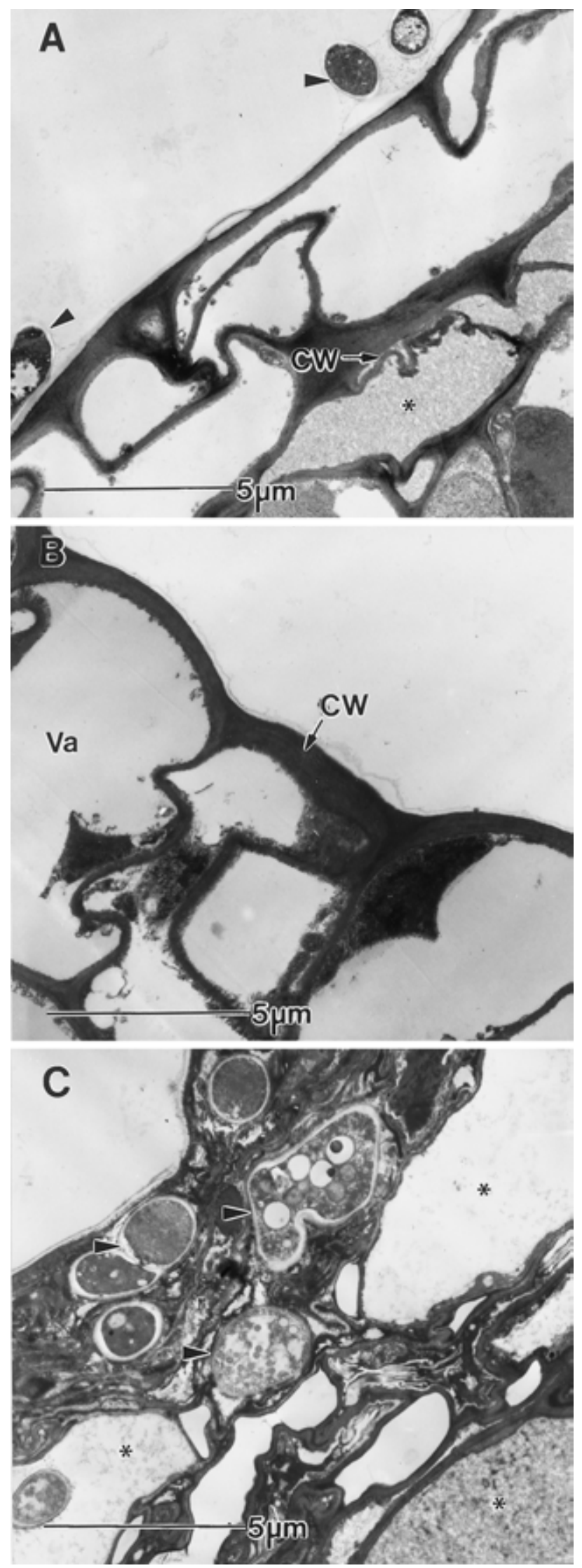

Fig. 9. Transmission electron micrographs of 6.0-mm-diameter blackberry floral buds infected by Cercosporella rubi and healthy buds. A, Surface of an infected carpel showing signs of host cell degeneration. The cell walls (CW and arrow) appear to be collapsing and the contents of the cells are becoming granular (asterisk). B, Surface of a healthy carpel showing uniform cells with large vacuoles (Va) and intact cell walls (CW and arrow). C, Area inside an infected carpel showing hyphae within collapsed host cells. Note cell walls are difficult to distinguish and some of the surrounding cells have varying densities of granulation (asterisks). Arrowheads point to hyphae of C. rubi. 
tant (3). Disease management schemes using chemicals have varied in efficacy with the fungicide used and timing of application $(10,13)$. Fungicide choice has been limited since benomyl (DuPont, Wilmington, DE) was removed from the market. Bordeaux mixture reduced disease severity, but was phytotoxic in several trials (13). Buckley and Waters (4) reported lower rosette incidence on blackberries treated with azoxystrobin (Syngenta, Greensboro, NC) and pyraclostrobin + nicobiofen (BASF, Research Triangle Park, NC) than on the benomyl-treated and untreated control plants.

\section{ACKNOWLEDGMENTS}

We thank G. Philley, G. Schnabel, and R. Baird for their critiques.

\section{LITERATURE CITED}

1. Berlyn, G. P., and Miksche, J. P. 1976. Botanical Microtechnique and Cytochemistry. Iowa State University Press, Ames.
2. Braun, U. 1995. A Monograph of Cercosporella, Ramularia and Allied Genera (Phytopathogenic Hyphomycetes), Vol. 1. IHWVerlag, Munich.

3. Buckley B., III, Moore, J. N., and Clark, J. R. 1995. Blackberry cultivars differ in susceptibility to rosette disease. Fruit Var. J. 49:235239.

4. Buckley, B., and Waters, J. C. 2003. Evaluation of fungicides for rosette control in blackberries, 2002. Fungic. Nematicide Tests 58:23.

5. Gupton, C. L., and Smith, B. J. 1997. Heritability of rosette resistance in blackberry. HortScience 32:940.

6. Hayat, M. A. 1981. Principles and Techniques of Electron Microscopy: Biological Applications, 2nd ed. University Park Press, Baltimore, MD.

7. Marroquin, E., Matta, F. B., Graves, C. H., Jr., and Smith, B. J. 1990. Relationship between blackberry flower/fungal development in blackberry infected with Cercosporella rubi. HortScience 25:1448.

8. Moore, J. N., and Skirvin, R. M. 1990. Blackberry management. Page 221 in: Small Fruit Crop Management. G. J. Galletta and D. G.
Himelrick, eds. Prentice Hall, Englewood Cliffs, NJ.

9. Parbery, D. G. 1996. Trophism and the ecology of fungi associated with plants. Biol. Rev. 71:473-527.

10. Plakidas, A. G. 1937. The rosette disease of blackberries and dewberries. J. Agric. Res. 54(4):273-303.

11. Sato, T. 1967. A modified method for lead staining of thin sections. J. Electron Microsc. 16:133.

12. Smith, B. J., and Fox, J. A. 1991. Rosette (double blossom). Pages 13-14 in: Compendium of Raspberry and Blackberry Diseases and Insects. M. A. Ellis, R. H. Converse, R. N. Williams, and B. Williamson, eds. American Phytopathological Society Press, St. Paul, MN.

13. Smith, B. J., and Killebrew, J. F. 2002. Epidemiology and control of blackberry rosette caused by the fungus Cercosporella rubi. Acta Hortic. 585:319-323.

14. Takeda, F., and Wisniewski, M. 1989. Organogenesis and patterns of floral bud developmen in two eastern thornless blackberry cultivars. J. Am. Soc. Hortic. Sci. 114:528-531.

15. Winter, G. 1885. Fusisporium (?) rubi Winter nov. spec. Hedwigia 24:258. 